\title{
Anatomical variations of the renal artery: a computerized tomographic angiogram study in living kidney donors at a Nigerian Kidney Transplant Center
}

\author{
Abayomi Aremu ${ }^{1}$, Martin Igbokwe ${ }^{1}$, Olalekan Olatise ${ }^{2}$, Ahmad Lawal $^{3}$, Kester Maduadi $^{4}$
}

\begin{abstract}
1. Urology Division, Zenith Medical and Kidney Centre, Gudu, Abuja, Nigeria.
2. Nephrology Unit, Zenith Medical and Kidney Centre, Gudu, Abuja, Nigeria.

3. Urology Division, Ahmadu Bello University Teaching Hospital, Zaria, Kaduna State, Nigeria.

4. Radiology Department, Zenith Medical and Kidney Centre, Gudu, Abuja, Nigeria.
\end{abstract}

\begin{abstract}
Background: Understanding of the renal vascular anatomy is key to a safe and successful donor nephrectomy, which ultimately impacts on the renal graft function and survival in kidney transplant recipients.

Objective: To report the various anatomical configurations of the renal artery identified in living kidney donors in a Nigerian kidney transplant institution .

Materials and Methods: The computerized tomography angiograms of 100 consecutive living kidney donors were prospectively reviewed over an 18-month period. Anatomical variations of the renal arteries including accessory arteries and early divisions were noted. Duration of surgery and ischemic time were recorded intra-operatively. Data analysis was carried out using IBM SPSS version 20.

Results: There were variations in renal artery configuration in 50 (50\%) cases, $32 \%$ were accessory renal arteries while $18 \%$ were early branches of the renal artery. The classical bilateral solitary renal arteries were found in $50(50 \%)$ of potential donors. There was statistically significant longer operating and ischemic time in donors with multiple renal arteries as compared with solitary arteries $(\mathrm{p}<0.05)$.

Conclusion: There are a wide variety of renal artery configurations seen in potential kidney donors. The classical solitary renal artery remains the commonest and most favourable configuration for donor nephrectomy and transplantation.

Keywords: Renal artery, variations, living kidney donors.

DOI: https://dx.doi.org/10.4314/ahs.v21i3.24

Cite as: Aremu A, Igbokwe M, Olatise O, Lawal A, Maduadi K. Anatomical variations of the renal artery: a computerized tomographic angiogram study in living kidney donors at a Nigerian Kidney Transplant Center. Afri Health Sci. 2021;21(3). 1155-1162. https:/ / dx.doi. org/10.4314/ahs.v21i3.24
\end{abstract}

\section{Introduction}

The anatomy of the renal artery plays a key role in selection of kidney donors for a renal transplant program ${ }^{1}$. The ideal renal artery for ease of vascular anastomosis is one which is solitary, of good diameter and length. Each kidney is classically supplied by a single renal artery, which arises as a lateral branch of abdominal aorta, between the levels of $1^{\text {st }}$ and $2^{\text {nd }}$ lumbar vertebrae ${ }^{2,3}$. The left renal artery is shorter in length while the longer right renal artery passes posterior to the inferior vena

\footnotetext{
Corresponding author:

Martin C Igbokwe, Urology Division, Zenith Medical and Kidney Centre, Gudu, Abuja, Nigeria.

Phone No: +2348034024229

Email address: martini4life@yahoo.com
}

cava (IVC) to gain access to the kidney at the renal hilum. Renal arteries give branches to the adrenal glands, renal pelvis and proximal ureters. After entering the hilum, each artery divides into five segmental end arteries which do not freely anastomose with each other. This therefore means that injury to a segmental renal artery would cause a segmental renal infarction. Computerized Tomography Angiography (CTA) is the investigation of choice for identifying the renal arterial anato$m y^{4}$. Studies have shown that the classical description of the renal vasculature, formed by one renal artery and vein are found in less than $25 \%$ of the population ${ }^{5,6}$. There have also been controversies in literature with regards the number of renal arteries and their branches ${ }^{7-9}$. Most often encountered morphological variations of renal artery are its variable number and unusual branches originating from $\mathrm{it}^{10-12}$. These variations are sometime incidentally found during autopsy or surgical operation. Terminologies like supranumerary, supplementary and (https://creativecommons.org/licenses/BY/4.0), which permits unrestricted use, distribution, and reproduction in any medium, provided the original work is properly cited. 
accessory have been used to describe the variable configurations of the renal artery. According to Sampaio and Passos, these arteries are referred to as multiple, since they are segmental vessels for the kidneys, without anastomoses between themselves and they should be named according to the territory supplied by them as- hilar, superior polar and inferior polar ${ }^{13}$. The knowledge of the possible variations in the configuration of the renal arteries is necessary for surgical management during donor nephrectomy, repair of abdominal aorta aneurysm, other retroperitoneal urological procedures and angiographic interventions. ${ }^{14-16}$

The aim of this study is to report the various anatomical configurations of the renal arteries in a cohort of randomised healthy kidney donors using computerized tomography angiogram.

\section{Materials and method}

This was a prospective, cross-sectional, hospital-based study conducted on 100 healthy living kidney donors in Zenith Medical and Kidney Center (ZMKC), Gudu, Abuja over an 18- month period (January 2018 to June 2019). Patients who were being planned for donor nephrectomy haven been found compatible with a recipient were recruited for this study. During the study period, the CT angiographic images were reviewed independently by two consultant urologists and a radiologist. All CT angiographic images were performed in the radiology unit of ZMKC using the unit protocol. The images were studied for the number of renal arteries originating from the abdominal aorta, the presence of early divisions into segmental arteries and presence of accessory arteries. For the purpose of this study, any division of the renal artery within $1 \mathrm{~cm}$ from its origin on the abdominal aorta was considered an early division while any other artery arising from the aorta or its branches to supply the kidney other than the main renal artery was termed an accessory artery. Tiny cortical branches were not taken into account as accessory renal arteries. Donor nephrectomies were all performed using a flank, extra-peritoneal approach using $11^{\text {th }}$ rib-transcostal or subcostal incisions while the recipient kidney transplant is performed in supine position via and extra-peritoneal approach using a Gibson incision. The findings were analyzed in both kidneys per patient and data was entered into a pre-designed proforma. Descriptive statistics were used to express the data with continuous variables summarized using arithmetic mean and standard deviation, while the categorical variables were summarized as proportions and frequencies. A p-value of less than 0.05 was considered significant. Data analysis was carried out using IBM Statistical Package for Social Sciences (SPSS) version 20.

\section{Result}

A total of 100 patients were successfully recruited for this study. Their ages ranged from 18 to 53 years with a mean age of $31.2 \pm 7.7$ years. Males accounted for $88 \%$ while the rest were females (Table 1). Ninety-eight $(98 \%)$ of the donors eventually underwent donor nephrectomy while 2 of the potential donors could not proceed with surgery due to sudden death (1) and a cerebro-vascular accident (1) in the recipients few hoursdays to surgery.

Table 1: Socio-demographic distribution of living kidney donors

\begin{tabular}{|c|c|}
\hline $\begin{array}{l}\text { Variable } \\
(\%)\end{array}$ & $\mathbf{n}$ \\
\hline \multicolumn{2}{|l|}{ Sex } \\
\hline Male & $88(88)$ \\
\hline Female & $12(12)$ \\
\hline \multicolumn{2}{|l|}{ Marital status } \\
\hline Single & 79 (79) \\
\hline Married & $21(21)$ \\
\hline \multicolumn{2}{|l|}{ Age Range } \\
\hline $11-20$ & $4(4)$ \\
\hline $21-30$ & $58(58)$ \\
\hline $31-40$ & $30(30)$ \\
\hline $41-50$ & $6(6)$ \\
\hline $51-60$ & $2(2)$ \\
\hline $61-70$ & $1(1)$ \\
\hline Total & $100(100)$ \\
\hline
\end{tabular}


Of the 100 CTAs studied, we observed that $50(50 \%)$ had the classical bilateral vascular renal arterial anatomy of a solitary renal artery with no accessory branch or early division (Figure 1). Among the other 50 patients
, $32(32 \% \%)$ had either unilateral or bilateral accessory renal arteries while $18(18 \%)$ had unilateral or bilateral early divisions of the renal artery. An accessory renal artery was found on the right side in 10 patients $(20 \%)$ and left side in 12 cases $(24 \%)$ respectively (Figure 2).

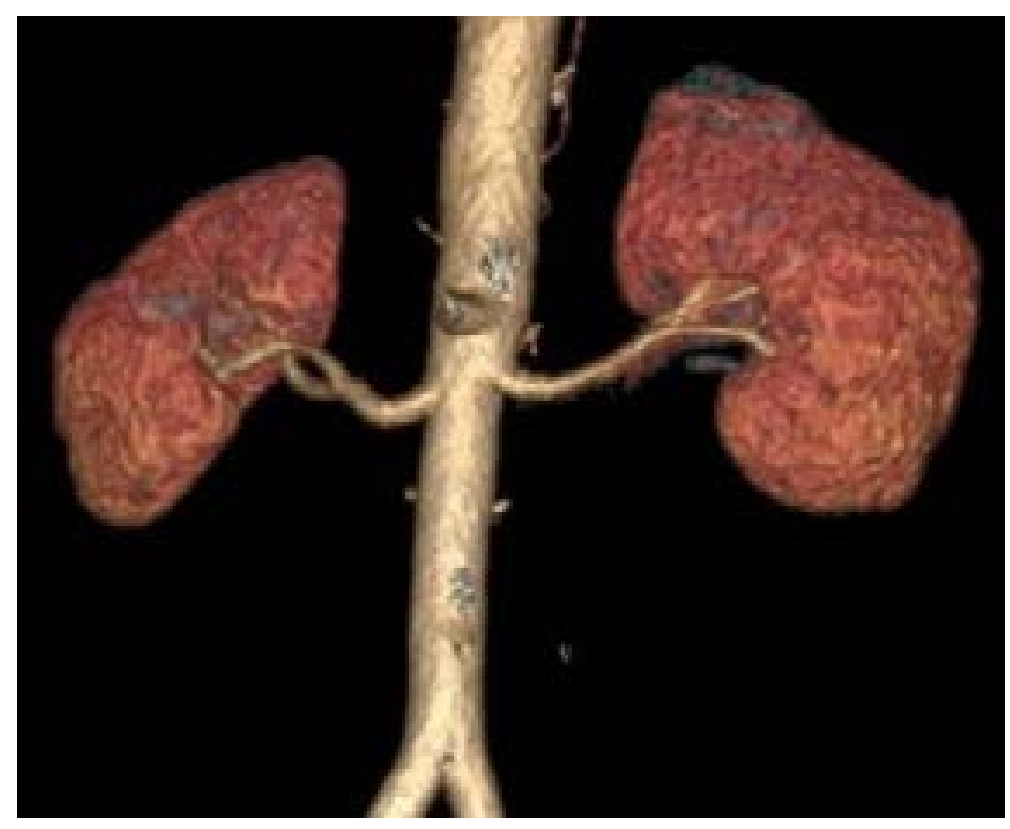

Figure 1: Showing single renal artery on both sides

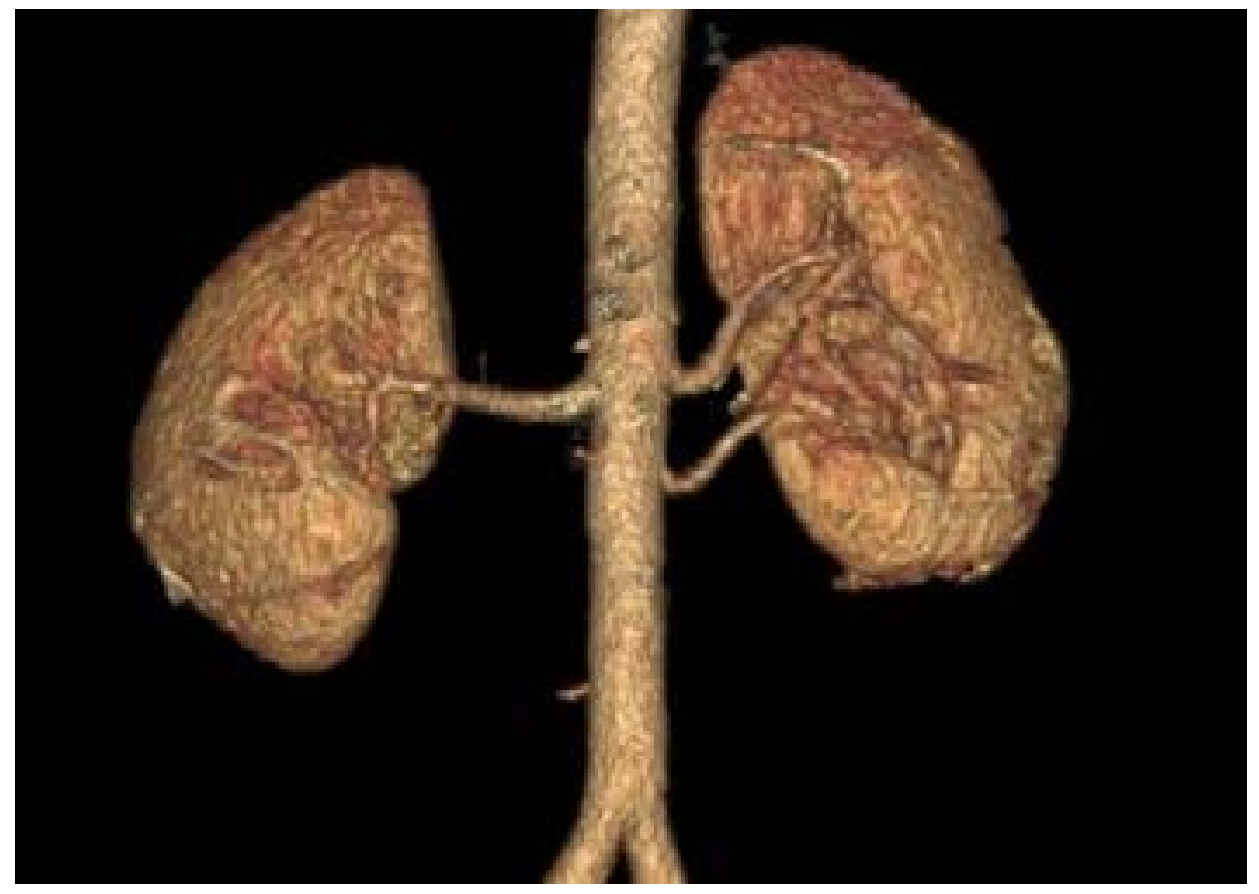

Figure 2: Showing an accessory hilar arteryto the left kidney

Bilateral accessory vessels were found in another $10 \mathrm{pa}-$ tients(Figure 3) with various rare variants seen in our series (Figure 4). Out of the 18(18\%) cases of early branching artery, 9\% and 8\% were found on the right and left side respectively while only one case of bilateral early branching was seen (Table 2). 


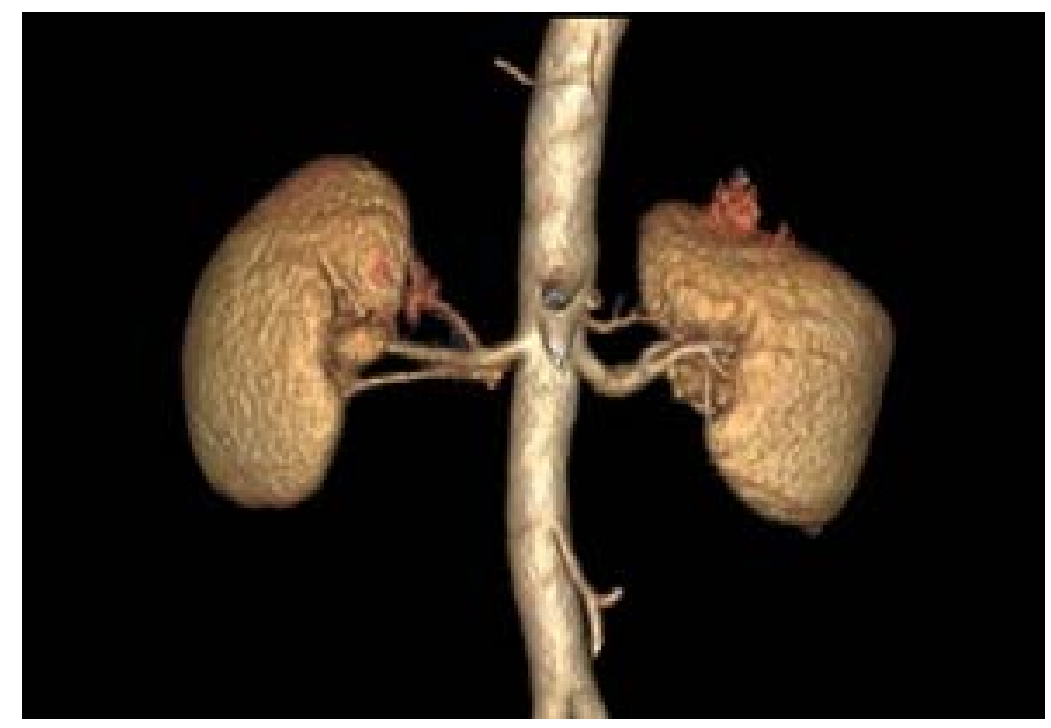

Figure 3: Bilateral accessory renal arteries

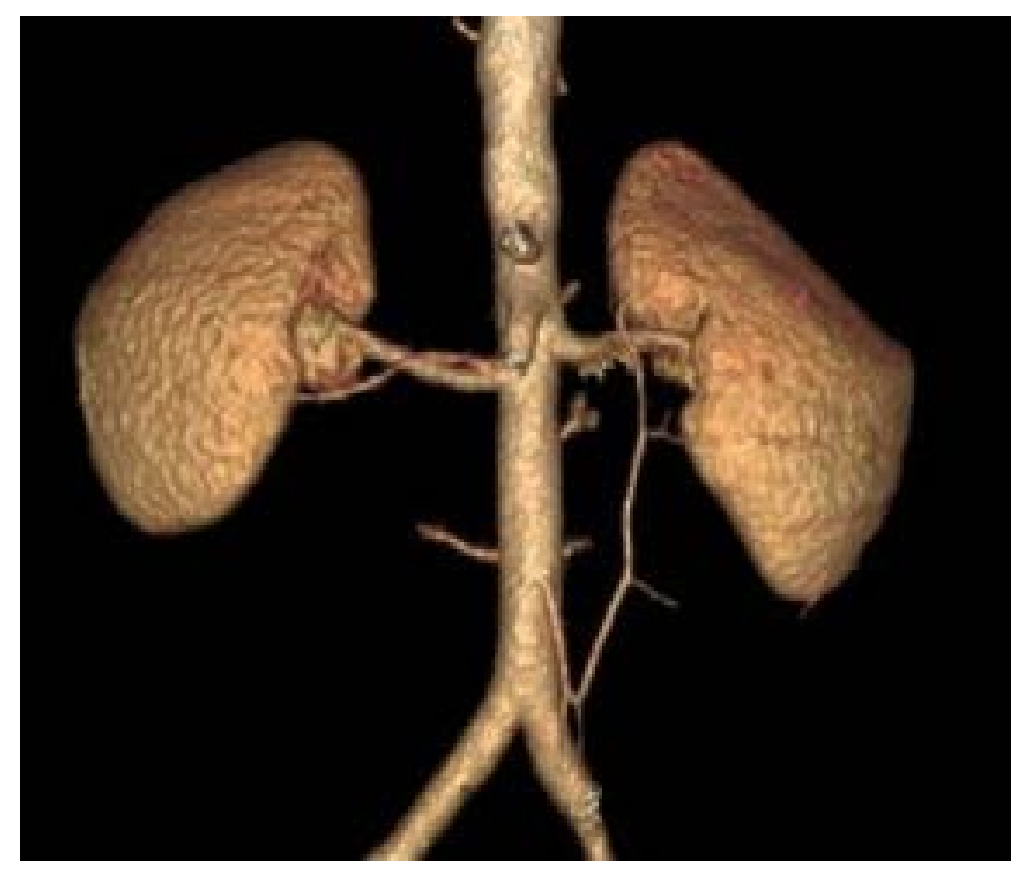

Figure 4: Unusual bilateral accessory renal arteries 
Table 2: Distribution of Renal Artery configuration findings on CT Angiogram

\begin{tabular}{|c|l|}
\hline VARIABLES & $\mathrm{N}(\%)$ \\
\hline $\begin{array}{l}\text { Normal and variations of renal artery Normal and variations of } \\
\text { renal artery (N = 100) }\end{array}$ & \\
\hline $\begin{array}{c}\text { Normal (Solitary renal arteries bilaterally) } \\
\text { Variations }\end{array}$ & $50(50)$ \\
\hline & $50(50)$ \\
\hline Distribution of variations in renal artery (N= 100) & \\
\hline Accessory renal artery & $32(32)$ \\
Early branching of renal artery & $18(18)$ \\
\hline & \\
\hline Distribution of accessory renal arteries & $10(10)$ \\
\hline Right accessory arteries & $12(12)$ \\
\hline Left accessory artery & \\
\hline Bilateral accessory renal arteries & $9(9)$ \\
\hline $\begin{array}{c}\text { Single accessory arteries bilaterally } \\
\text { Double accessory renal arteries bilaterally }\end{array}$ & $1(1)$ \\
\hline Anatomical distribution of accessory renal arteries (N = 100) \\
Single hilar \\
Right Side \\
Left Side & $80(80)$ \\
Double hilar & $76(76)$ \\
Right & $6(6)$ \\
Left & $11(11)$ \\
Right & $5(5)$ \\
Left & $2(2)$ \\
Right & $9(9)$ \\
Left & $10(10)$ \\
Right & - \\
\hline Left & $1(1)$ \\
\hline
\end{tabular}

The presence of both accessory renal arteries and early divisions were higher among kidneys of male donors when compared to female donors $(p=0.002$ and $\mathrm{p}=0.003$ respectively).

There was a co-existence of early division and accessory renal arteries in 2 patients (Figure 5).

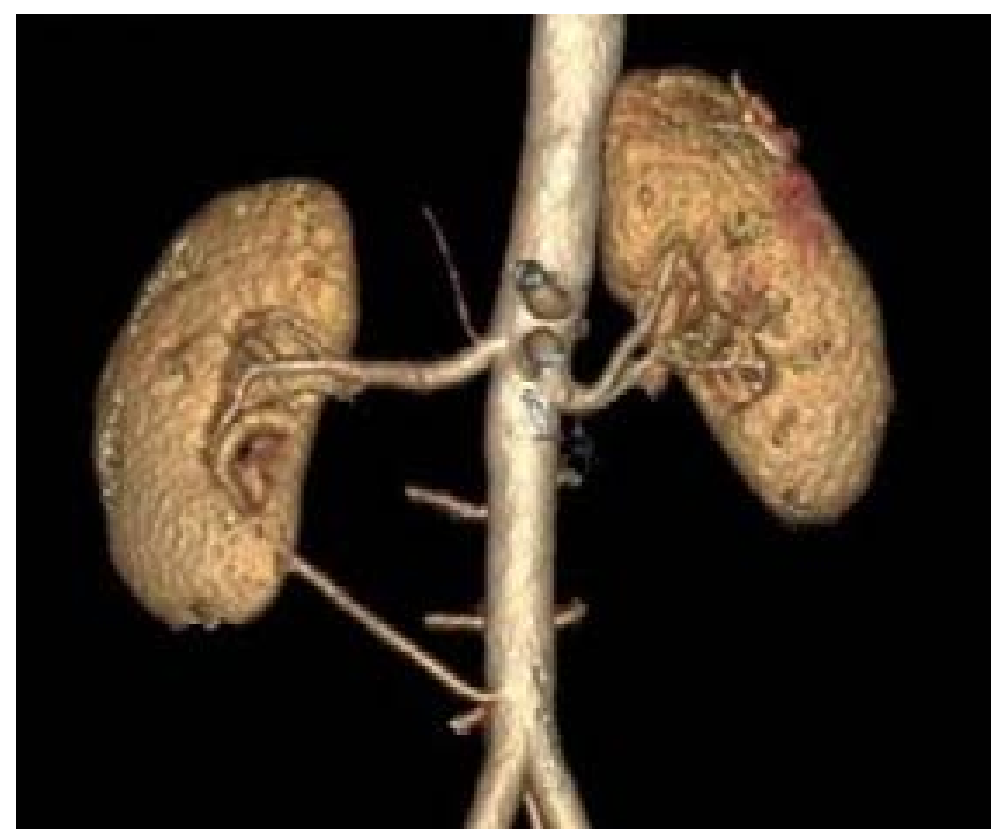

Figure 5: Co-existence of accessory right renal artery and left early division of renal artery 
In the 10 cases where there were bilateral accessory renal arteries, the side with larger diameter accessory renal artery was selected for donor nephrectomy. These renal allografts when extracted intra-operatively required meticulous bench vascular surgery. 6 of allografts had bench artero-arterostomy in end-to-side fashion to produce a common stump using prolene $6 / 0$ sutures while 4 others had 2 separate annastomosis of the renal arteries to the external iliac artery in end-to-side fashion. All kidneys had good perfusion and renal function on the table. There was significantly longer surgery time, warm and cold ischemic time in renal allografts with multiple arteries $(p<0.05)$ (Table 3). These findings significantly affected our decision of the renal unit to harvest from the donor for transplantation. There was an inadvertent transection of an early division of the renal artery in 1 donor nephrectomy allograft with consequent devascuarisation of about $20 \%$ of the allograft requiring bench re-anastomosis of the transected segments of the artery with satisfactory outcome. . There was a significantly longer total surgery time, warm and cold ischemic time among kidney donors with solitary renal arteries when compared to multiple (accessory/ early branches) renal arteries (Table 3).

Table 3: Breakdown of Mean durations of surgery time and ischemic time

\begin{tabular}{|c|l|l|}
\hline Variable & $\begin{array}{l}\text { Mean duration (minutes) } \\
+/- \text { Standard deviation }\end{array}$ & P value \\
\hline $\begin{array}{c}\text { Total Surgery time } \\
\text { Solitary renal artery } \\
\text { Multiple renal arteries }\end{array}$ & $\begin{array}{l}115+/-15.4 \\
135+/-23.0\end{array}$ & $\mathbf{0 . 0 1 0}$ \\
\hline $\begin{array}{c}\mathbf{1}^{\text {st }} \text { Warm Ischemic time } \\
\text { Solitary renal artery } \\
\text { Multiple renal arteries }\end{array}$ & $\begin{array}{l}2.5+/-0.6 \\
4.5+/-1.2\end{array}$ & $\mathbf{0 . 0 1 4}$ \\
\hline $\begin{array}{c}\text { Cold ischemic time } \\
\text { Solitary renal artery } \\
\text { Multiple renal arteries }\end{array}$ & $22+/-16.5$ & $\mathbf{0 . 0 0 5}$ \\
\hline $\mathbf{2}^{\text {nd }}$ Warm Ischemic time \\
Solitary renal artery \\
Multiple renal arteries & $43+/-20.0$ & $55+/-20.0$ \\
\hline
\end{tabular}

\section{Discussion}

The knowledge of the detailed anatomy of the renal arteries plays an important role in planning major surgical procedures like live donor nephrectomy. The need for CT angiographic studies can therefore not be over-emphasized in this regards. Presence of an accessory renal artery connotes a more challenging surgical prospect for both the donor nephrectomy and allograft implantation surgeons. In cases where the kidney with an accessory renal artery cannot be avoided for donor nephrectomy ( especially when they occur bilaterally), there is a need for meticulous dissection of the accessory arteries to ensure good length for ease of anatomosis. This will also translate to a longer cold and second warm ischemic time as there may be need for a double-barrel bench anastomosis of the accessory arteries or performing multiple vascular anatomosis with the iliac artery of choice on the recipient. Considering these challenges, it is usually the surgeons's preference to harvest a renal unit with the classical configuration of the renal artery. Our study revealed that 1 in 2 patients had the classical single bilateral renal arteries which was similar to findings by Kumaresan et al where $49 \%$ had the normal anatomy ${ }^{17}$. The high incidence of renal artery variations regarding their origin and number as found in the index study has been similarly reported by many researchers ${ }^{7-9}$. The various types of accessory renal arteries, their positions, method of entry to the kidney and its segmentation were studied extensively by Sykes $(1963)^{18}$. Obstruction to any of these vessels leads to infarction of the segment of the kidney supplied..$^{13}$ Due to the important clinical correlation of these real arterial variations, terminologies like hilar, superior polar and inferior polar renal arteries have been described in literature in order to better qualify them.

Similar to our finding on the prevalence of early branching and accessory renal arteries $(18 \%$ \& $32 \%$ respectively), Budhiraja et al in an Indian cadaveric study and Kumaresan et al reported close results. This how- 
ever slightly differed from a study by Gumus et al who reported early division in $27 \%$ and accessory renal artery in $27 \%{ }^{19}$. This may however be as a result of racial differences asrenal artery variations are more common in Africans than Indians ${ }^{20,21}$. Bilateral early branching which was seen in only $1 \%$ in the index study is also a rare finding in literature (ref). Intra-operatively during donor nephrectomy and renal pelvis surgeries, superior and inferior polar extra hilar branches can be injured during mobilization ${ }^{13}$. Inferior polar artery injuries can be a cause of ureteropelvic junction obstruction 10 . Nowadays, allografts with multiple renal arteries have become a necessity to maintain donor pool ${ }^{22}$, but its outcome is still a matter of discussion. Some surgical scholars opine that multiple renal arteries increase the chances of acute rejection and poor graft functions ${ }^{23,24}$, while others like Benedetti et $\mathrm{al}^{25}$ did not find significant difference with regard to acute rejection rate in grafts with single versus multiple arteries. It is however agreed generally that allografts with multiple renal arteries have a higher risk of renal artery stenosis ${ }^{26}$ and technical difficulties for surgeon performing transplant operation ${ }^{7,27}$

\section{Conclusion}

Fifty percent of living kidney donors have either early divisions or accessory renal arteries .It has become increasingly important for kidney transplant surgeons to familiarize themselves with the anatomical variations of the renal artery and its correlation with surgery.

\section{Recommendation}

There maybe a need to carry out a larger multi-centered and international study in order to assess a larger population of donors so as to have a more robust and representative result.

\section{Acknowledgement}

We appreciate the radiology department of Zenith Medical and Kidney center for the good quality images for this manuscript.

\section{Conflict of interest}

None.

\section{Source of Funding}

None.

\section{References}

1. Turba UC, Flacker R, Bozlar U, Hagspiel KD. Normal renal arterial anatomy assessed by multidetector CT angiography: are there differences between men and women? Clin Anat. 2009;22(2):236-42.
2. Beregi JP, Mauroy B, Willoteaux S, Mourniervehier C, Remyjardin M, Francke J. Anatomic variation in the origin of the main renal arteries: spinal CTA evaluation. European Journal of Radiology. 1999;9(7):1330-4.

3. Ozkan U, Oguzkurt L, Tercan F, Kizilkilic O, Koc Z, Koca N. Renal artery origins and variations: angiographic evaluation of 855 consecutive patients. Diagnostic and Interventional Radiology. 2006;12(4):183-6.

4. Thatipelli MR, Sabater EA, Bjarnason H, McKusick MA, Misra S. CT angiography of renal artery anatomy for evaluating embolic protection devices. J Vasc Interv Radiol. 2007;18(7):842-46.

5. Awojobi OA, Ogunbiyi OA, Nkposong EO. Unusual relationship of multiple renal arteries. Urology. 1983;21(2):205-6.

6. Cicekcibasi AE, Ziylan T, Salbacak A, Seker M, Buyukmumcu M, Tuncer I. An investigation of the origin, location and variations of the renal arteries in human fetuses and their clinical relevance. Annals of anatomy. 2005;187:421-7 PubMed .

7. Shakeri AB, Tubbs RS, Shoja MM, Pezeshk P, Farahani RM, KhakI AA, et al. Bipolar supernumerary renal artery. Surg Radiol Anat. 2007;29(1):89 PubMed -92.

8. Rao M, Bhat SM, Venkataramana V, Deepthinath R, Bolla SR. Bilateral prehilar multiple branching of renal arteries: a case report and literature review. Kathmandu University Medical Journal. 2006;4(3):345-8.

9. Satyapal KS, Haffejee AA, Singh B, Ramsaroop L, Robbs JV, Kalideen JM. Additional renal arteries incidence and morphometry. Surg Radiol Anat.2000;23(1):33 PubMed -8.

10. Shoja MM, Tubbs RS, Shakeri A, Ardalan MR, Ardabili BR, Ghabili K. Asymptomatic bilateral ureteropelvic junction obstruction due to supernumerary renal arteries. Saudi Journal of Kidney Disease and Transplantation. 2008;19(5):806-8.

11. Dhar P, Lal K. Main and accessory renal arteries -a morphological study. Italian Journal of Anatomy and Embryology. 2005;110(2):101-10.

12. Rusu MC. Human bilateral doubled renal and testicular arteries with a left testicular arterial arch around the left renal vein. Romanian Journal of Morphology and Embryology. 2006;47(2):197-200.

13. Sampaio FJ, Passos MA. Renal arteries: anatomic study for surgical and radiological practice. Surg Radiol Anat. 1992;14(2):113-7.

14. Nathan H, Glezer L. Right and left accessory renal arteries arising from a common trunk associated with unrotated kidneys. Journal of Urology. 1984;132(1):7-9.

15. Olsson $\mathrm{O}$, Wholey M. Vascular abnormalities in gross anomalies of kidneys. Acta Radiologica Diagnosis. 1964;2:420-32 PubMed. 
16. Satyapal K, Haffejee A, Singh B, Ramsaroop L, Robbs JV, Kalideen JM. Additional renal arteries: incidence and morphometry. Surgical and Radiological Anato$m y$, . 2001;23(1):33-8.

17. Kumarasen M, Sakaran PK, G. K, Gunapriya R, Shilpakala LB, Sudakshina C. Variations in Branching Pattern of Renal Artery in Kidney Donors Using CT Angiography. Journal of Clinical and Diagnostic Research. 2016;10(3):01-3.

18. Sykes D. The arterial supply of the human kidney with special reference to accessory arteries. British Journal of Surgery. 1963;50:368-74.

19. Gumus H, BrdalOzdemir E, Cetincakmak ML, Tekbas G. Variations of renal artery in 820 patients using 64-detector CT-Angiography. Renal Faliure. 2012;34:28690 PubMed.

20. Abrams BE. Renal angiography: Techniquesand hazards; anatomic and physiologicconsiderations. Boijsen E Abrams' angiography 4th ed. 1997; Philadelphia: Little, Brown and Company(In: Baum S,): 1101-31.

21. Kadir S. Atlas of normal and variant angiographic anatomy. Kidneys 1991;Saunders Company:387-429.
22. Kadolani Y, Okamoto M, Nobori S, Kaibara S. Management and outcome of living kidney grafts with multiple arteries. Surgery Today. 2005;35:459-66 PubMed . 23. Gupta V, Kotgiwar S, Trivedi S, Deopujari R, Singh V. Bilateral variation in renal vasculature. International Journal of Anatomical variations. 2010;3:53-5.

24. Brannen GE, Bush WH, Correa RJ, Gibbons RP, Cumes DM. Microvascular management of multiple renal arteries in transplantation. The Journal of Urology. 1982;128:112-5 PubMed .

25. Benedetti E, Troppmann C, Gillingham K, Sutherland DE, Payne WD, Dunn DL, et al. Short and long term outcomes of kidney transplants with multiple renal arteries. Annals of Surgery. 1995;221(4):406 PubMed $-14$.

26. Kamali K, Abbasi MA, Ani A, Zargar MA, Shahrokh H. Renal transplantation in allografts with multiple versus single renal arteries. Saudi Journal of Kidney Disease and Transplantation, 2012;23(2):246-50.

27. Shoja MM, Tubbs RS, Shakeri AB, Oakes WJ. Origins of the gonadal artery: embryologic implications. Clinical Anatomy. 2007;20(4):428 PubMed -32. 